\title{
Exploring physical attributes of walkability from perspective of blind pedestrians
}

\author{
Russ Bona Frazila ${ }^{1}$ and Febri Zukhruf ${ }^{*}$ \\ ${ }^{1}$ Department of Civil Engineering, Institut Teknologi Bandung, Jl. Ganesha No. 10, Bandung, 40132, Indonesia
}

\begin{abstract}
Access has become a crucial issue for the persons with disabilities (PWDs), in which the inconvenient transportation facilities is contributed to the dependent living issue of PWD, specifically the visual impaired person. As a primary aspect of transportation, the walking facilities further needs to be carefully considered for facilitating their moving activities. Recently, the effect of built environment on walking behavior has obtained significant attention, which is generally constructed within the framework of walkability concept. The walkability has been extensively used for evaluating the physical attributes of pedestrian facilities by comparing it to the walker perception. Hence, the evaluation result can directly answer the needs of pedestrian. Despite of their recent research achievements, the walkability concept is mostly unsuccessful to take into account the blind walker characteristics. This paper then explore physical attributes of walkability environment in order to provide the friendly pedestrian facilities for the blind pedestrian, which is rarely explored. The research is established based on the blind walker perspectives within the micro-level analysis that incorporates a smaller unit of measurement (i.e., the street-level physical attributes). The physical attributes result are thus potentially to be utilized for analyzing the required pedestrian facilities for the blind pedestrians.
\end{abstract}

\section{Introduction}

People with disabilities (PWDs) practically meet some difficulties for accessing the transportation facilities ([1]), which directly influence their mobility. The inaccessibility of such facilities then limits their opportunities to participate in various types of social and economic activities, and hence, the access improvement becomes a necessary element for increasing the quality life of PWDs. Practically PWDs can be divided into several categories, namely, wheelchair users, blind and visually impaired people, deaf and hearing impaired people, walking impaired people, people with other handicaps, elderly people, children and people of short or tall statue. The researches on transportation accessibility generally pay attention to the first two categories of PWDs (i.e., wheelchair user, blind and visually impaired people (VIP)).

For tackling such issues, several studies have been conducted. Pecchini and Giuliani [2] surveyed the crossing behavior of PWDs and they proposed the design recommendation. The other experiments have been also implemented for capturing the PWDs behavior, such as, walking speed of VIPs [3], stair evacuation speed [4], doorways capacity by considering PWDs and elderly people ([5]). The specific research relating to the blind and VIP is also conducted, which is mainly focused on the autonomously navigation, such as, accessible smartphones for blind user [6], Acoustic way finding [7],
ZebraRecognizer [8], traffic lights detection on smartphones [9], and sonification of guidance data [10].

Despite its recent development of PWDs and VIP pedestrian studies, the elaboration of built environment on walking behavior of VIPs are still left behind, compare to the non-PWDs studies (e.g., [11], [12]). Such elaborations are practically implemented within the framework of walkability concept, where the built environment evaluation have been constructed in the meso-level or the micro-level. The level is differed by its detail aggregation, for example the meso level evaluated the walkability in the area level ([13], [14]), whereas the micro-level measure the street-level physical attributes, such as the presence of trees, the width of sidewalks, and the quality of streets (e.g., [15]).

This paper then present the evaluation of physical attributes, which govern the walkability environment in order to provide the friendly pedestrian facilities for the blind and VIPs pedestrian, which is rarely explored. Furthermore, the blind walker perspectives is elaborated within the micro-level analysis for investigating a smaller unit of street-level physical attributes. The attributes result are thus potentially to be involved for analyzing the required pedestrian facilities for the blind and VIP pedestrians.

In the following section, the method is described, while in the third section, the blind walker characteristics are firstly resented, before elaborating the physical attributes of pedestrian environment in the fourth

\footnotetext{
* Corresponding author: febri.zukhruf@ftsl.itb.ac.id
} 
section. Finally, in the fifth section, the methodologies, results, and analyses in the paper are summarized.

\section{Walkability Concept}

The main objective of paper is to elaborate the physical attribute that govern the walkability perception of blind pedestrian. The walkability analysis is constructed based on the micro-level analysis, in which two different surveys are designed, namely, a blind walker perception survey, and a physical survey for gathering the physical attributes that governing the walkability perception.

Since the study incorporates a micro-level analysis, the analysis is considered by measuring the micro scale of street physical attributes, for instance, width of side walk, number of commercial uses, average building width, and other physical attributes ([16]). The microlevel is possibly obtained a huge attribute combination, which is not practical to be investigated. Therefore, the physical attributes is elaborated by assuming there is a linear correlation between the attributes and the walkability perception (see Eq. (1)). Furthermore, the important attributes are selected based on the step wise based approach.

$$
Y^{n}=c_{1} y_{1}^{n}+c_{2} y_{2}^{n}+\ldots+c_{m} y_{m}{ }^{m}
$$

where :

$Y \quad$ : perception value of walkability component- $n$

$y_{m}$ : physical attributes- $m$ that possibly govern the walkability perspective,

$c_{m} \quad$ : relative importance of each physical attributes- $m$.

Since the walkability is certainly influence by several components, it is importance to discover the walkability components that strongly affect the walkability perception of blind pedestrian. Therefore, the important walkability component is determined based on the blind walker perception about the importance facilities that need to be provided. In order to get more comprehensive view of walker need, the question is designed based on the pair wise comparison approach. The physical attributes are explored based on the interview and the street physical survey in the four pedestrian routes. The routes are selected based on the experience of respondents, where its several performance indicators are assessed by respondents. The assessment is then compared to the current situation of physical attribute to investigate the important attribute that constructs the walkability perception.

\section{Blind Walker Characteristics}

Before turn into the deep discussion relating to the physical attributes of walkability for the blind walker, this paper firstly elaborate the walking characteristic of blind persons. The characteristics is corresponded to the possible walking time, the group walking behavior, the transportation modes used and its transportation cost. Figure 1 illustrates the different perception of possible walking time between blind and non-blind pedestrians. The blind pedestrians perceive the less walking time than the non-blind pedestrians, in which the most of blind pedestrian only possible walk around 10 minutes, below the non-blind pedestrians that can averagely walk in around 20 minutes. Furthermore, the seeing pedestrians believe that they can reach up to 80 minutes walking on the farthest, where the blind pedestrians considers only a half walking time of non-blind pedestrians.

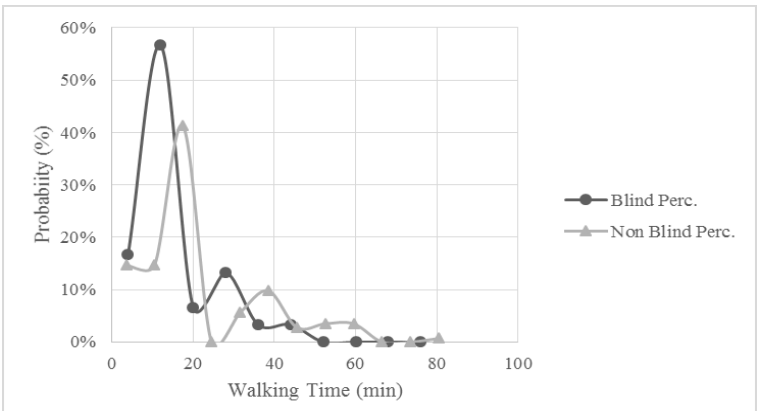

Fig. 1. Possible walking time perception of blind and non-blind pedestrians.

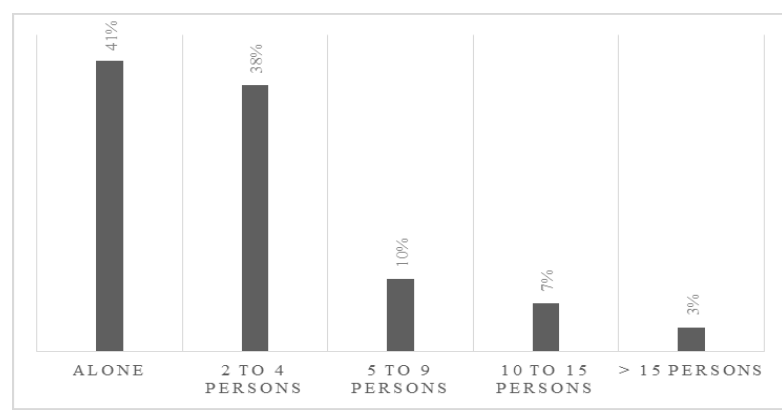

Fig. 2. Group Walking of Blind Pedestrians

The survey results also indicate that the blind pedestrian frequently walks within the group than conducts the alone walking trip (see Figure 2). To support their travel trip, the public transportation mode (i.e., Bus and Paratransit) is selected as the main transportation modes for the blind walkers. However, the end to end walking trip still gains a big portion, which can be interpreted as the inconvenient public transport service.

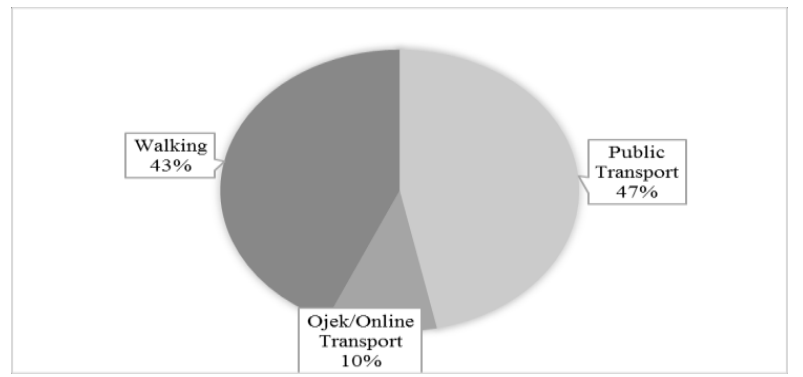

Fig. 3. Transportation Mode Used by Blind

In term of transportation cost, the blind mostly spends less than Rp. 10,000 for single trip, where for the longer trip they can be incurred up to Rp. 85.000 per trip by using online transportation modes. 


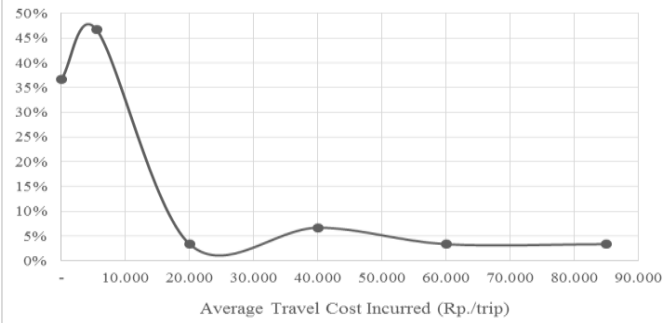

Fig. 3. Average Travel Cost Incurred by Blind.

\section{Physical Attributes Walkability for Blind Pedestrian}

The further stage is conducted by elaborating the walkability components for the blind pedestrian. Due its physical limitation, the walkability components may differ to the non-blind pedestrians. This paper then explores the walkability components, which is derived from the required facilities.

The required facilities are examined by conducting the pair wise comparison interview to the blind pedestrians. The width of sidewalk, its pavement condition, crossing facilities, sidewalk level, tactile paving, braille information, safety and security facilities are selected as the main facilities. The results shows that the security and safety facilities is perceived as the most important facilities to the blind pedestrians.

In addition, the tactile paving and braille information in the walking built environment is significantly needed, which could provide the direction and guidance to the blind walker. As it can be inferred from the table above, the blind pedestrians also pay more attention to the pavement condition than the width of side walk, which can easily be understood by taking into consideration their physical shortcomings.

Table 1. Required Facilities for Blind Pedestrians.

\begin{tabular}{|c|c|}
\hline Facilities Components & $\begin{array}{c}\text { Weight of } \\
\text { Importance }\end{array}$ \\
\hline Width of Sidewalk & 0,11 \\
\hline Sidewalk Pavement Condition & 0,15 \\
\hline Crossing Facilities & 0,16 \\
\hline Sidewalk Level & 0,14 \\
\hline $\begin{array}{c}\text { Tactile Paving and Braille } \\
\text { Information (Physical Guidance) }\end{array}$ & 0,22 \\
\hline Safety and Security & 0,23 \\
\hline
\end{tabular}

The interview and facilities surveys are also implemented for investigating the built environment of pedestrian facilities that construct the walkability components of blind pedestrians. To obtain more comprehensive view, the current performances of walkability components, which are assessed by the blind pedestrians, are compared to the physical attribute of pedestrian facilities. The attributes is listed by Park et al. [16], for instances, width of side walk, number of commercial uses, average building width, and etc. Such comparisons allow the further investigation for discovering the attributes that form the walkability components for the blind pedestrians. By assuming that there is a linear correlation between physical attributes and the blind pedestrian perception, and hence, it is possibly used for prioritizing the required pedestrian facilities to smoothly flow the blind pedestrians.

The width of sidewalk is firstly discussed by counting the total and effective width of side walk. The effective width can be easily defined as the total width reduces by the obstacle that decrease the usage of total width. This study thus studied how the perception of blind walker to the sidewalk width by considering those factors. Despite its less statistic performance, which is merely caused by number of respondent, by comparing the perception of blind walker to the physical indicator, it is interesting to find that the blind walker more considers the effective width rather than the total width. As it is illustrated in Table 2, the wider effective width is positively correlated to the satisfaction perception of blind pedestrians.

Table 2. Regressions result of sidewalk width component

\begin{tabular}{lcccc}
\hline \multirow{2}{*}{ Variables } & \multicolumn{4}{c}{ Blind Walker Perspectives } \\
\cline { 2 - 6 } & Coeff. & Std. Err. & t & Sig \\
\hline Total width (m) & $-0,20$ & 0,54 & - & 0,72 \\
Effective width (m) & 0,37 & 0,91 & 0,41 & 0,69 \\
Constant & 2,34 & 0,36 & 6,58 & 0,00 \\
\hline F Statistic & & & & 0,26 \\
Significance F & & & & 0,62 \\
\hline
\end{tabular}

For examining the factor that build the walkability component of pavement condition, the number of potholes in the sidewalk and the condition of tactile pavement is associated to the convenient perception from the blind pedestrians. Table 3 indicates that the pavement satisfaction condition is more contributed from the tactile pavement condition than the number of sidewalk potholes. This phenomena is merely caused by the behavior of blind pedestrian that practically follow the tactile pavement as the guidance, and hence, the damage of tactile pavement toward to reduce their perception about the condition of sidewalk pavement.

Table 3. Regressions result of sidewalk pavement condition

\begin{tabular}{lllll}
\hline \multirow{2}{*}{ Variables } & \multicolumn{4}{c}{ Blind Walker Perspectives } \\
\cline { 2 - 5 } & Coeff. & Std. Err. & t & Sig \\
\hline Number of sidewalk & 0,12 & 0,47 & 0,25 & 0,80 \\
potholes/100 m(unit) & & & \\
Tactile paving condition $\left.{ }^{*}\right)$ & 0,82 & 0,37 & 2,19 & 0,04 \\
Constant & 1,00 & 0,66 & 1,51 & 0,14 \\
\hline F Statistic & & & & 2,75 \\
Significance F & & & & 0,08 \\
\hline
\end{tabular}

${ }^{*}$ : 1 : poor condition ; 2 : moderate condition ; $3:$ good condition

The factor that build the perception about crossing facilities is also analyzed. Since most of traffic light in Indonesia is not installed by the sound equipment, this 
study only consider the number of zebra crossing for seeking the facilities that associate with the crossing components. Table below infers that there is a positive correlation between the numbers of zebra crossing facilities with the easiness perception of crossing for blind walkers.

Table 4. Regressions result of crossing components

\begin{tabular}{lccccc}
\hline \multirow{2}{*}{ Variables } & \multicolumn{4}{c}{ Blind Walker Perspectives } \\
\cline { 2 - 6 } & $\begin{array}{c}\text { Coef } \\
\text { f. }\end{array}$ & $\begin{array}{c}\text { Std. } \\
\text { Err. }\end{array}$ & t & Sig \\
\hline $\begin{array}{l}\text { Number of zebra } \\
\text { crossing/300 m (unit) }\end{array}$ & 0,33 & 0,13 & 2,48 & 0,02 \\
Constant & 1,83 & 0,33 & 5,52 & 0,00 \\
\hline F Statistic & & & & 6,16 \\
Significance F & & & & 0,02 \\
\hline
\end{tabular}

Table 5 describes the regression result which compares the blind pedestrian perspective about the physical guidance satisfactions with the tactile existences and its condition. Since the braille information and the sound guidance equipment are not available in the study area, the physical guidance is more concentrated to the tactile guidance. The result imply that the existence of pavement tactile should be united with its good condition in order to fulfill the blind pedestrian needs.

Table 5. Regressions result of physical guidance components

\begin{tabular}{|c|c|c|c|c|}
\hline \multirow{2}{*}{ Variables } & \multicolumn{4}{|c|}{ Blind Walker Perspectives } \\
\hline & $\begin{array}{r}\text { Coeff } \\
.\end{array}$ & $\begin{array}{l}\text { Std. } \\
\text { Err. }\end{array}$ & $\mathbf{t}$ & Sig \\
\hline Tactile condition & 0,78 & 0,33 & 2,35 & 0,03 \\
\hline $\begin{array}{l}\text { Existence of } \\
\text { pavement tactile *) }\end{array}$ & 0,10 & 0,29 & 0,33 & 0,74 \\
\hline Constant & 1,09 & 0,47 & 2,35 & 0,03 \\
\hline F Statistic & & & & 3,36 \\
\hline Significance F & & & & 0,05 \\
\hline
\end{tabular}

$\left.{ }^{*}\right)$ : 1 : tactile pavement exist ; 0 : tactile pavement is not exist

The sense of security in the pedestrian facilities is practically difficult to be assessed, since it is mostly affected by the other aspects. However, this paper try to draw the security issue by correlating it with the existence of others. The number of nearby house and commercial are then investigated for illustrating the existence of others. The results show that the increasing number of nearby commercial probably improve the sense of security for the blind pedestrians.

The other issues, which need to be carefully considered for the blind pedestrian, is the side walk level changes. The changes within the side walk facilities will bring some difficulties to the blind pedestrian. Therefore, the study try to capture the factor that influence the perception of blind walker about the level changes. Table 7 show that the number of intermediaries, which force the walker to consider the change of sidewalk level, are negatively related to the blind walker perception. The similar situation occurred for the changing elevation. Thus, it can be simply concluded that the blind walker will find more difficulties if the number of intermediaries increase, as well as the increment of elevation changing. Furthermore, the existence of chair is interestingly related to the positive perception about the side walk level. This fact may be seen as the blind walker prefer to use chair for taking a rest.

Table 6. Regressions result of security issues

\begin{tabular}{llllll}
\hline \multirow{2}{*}{ Variables } & & \multicolumn{4}{c}{ Blind Walker Perspectives } \\
\cline { 2 - 6 } & & $\begin{array}{r}\text { Coe } \\
\text { ff. }\end{array}$ & $\begin{array}{c}\text { Std. } \\
\text { Err. }\end{array}$ & t & Sig \\
\hline $\begin{array}{l}\text { Number of nearby } \\
\text { house/100 m (unit) }\end{array}$ & 0,09 & 0,08 & 1,24 & 0,23 \\
$\begin{array}{l}\text { Number of nearby } \\
\text { commercials/100 m (unit) }\end{array}$ & 0,01 & 0,01 & 1,44 & 0,16 \\
Constant & 1,52 & 0,49 & 3,09 & 0,00 \\
\hline F Statistic & & & & 1,73 \\
Significance F & & & & 0,20 \\
\hline
\end{tabular}

Table 7. Regressions result of side walk level

\begin{tabular}{lllll}
\hline \multirow{2}{*}{ Variables } & \multicolumn{4}{c}{ Blind Walker Perspectives } \\
\cline { 2 - 5 } & Coeff. & $\begin{array}{l}\text { Std. } \\
\text { Err. }\end{array}$ & t & Sig \\
\hline $\begin{array}{l}\text { Avg. number of } \\
\text { intermediaries (per 100 } \\
\text { m) }\end{array}$ & $-0,04$ & 0,16 & $-0,26$ & 0,80 \\
$\begin{array}{l}\text { Changes in elevation } \\
\text { (per 100 m) }\end{array}$ & $-0,02$ & 2,45 & $-0,01$ & 0,99 \\
$\begin{array}{l}\text { Existence of chair } \\
\text { Constant }\end{array}$ & 0,03 & 0,87 & 0,03 & 0,97 \\
\hline F Statistic & 2,81 & 1,32 & 2,12 & 0,04 \\
Significance F & & & & 0,06 \\
\hline
\end{tabular}

Putting together the analysis of walkability component, table below summarize the important built environment factors for forming the walkability of blind walker. As can be inferred from Table 8, it is very important to provide several physical indicator for smoothly flowing the blind walker, for instance, the sufficient effective width, the existence of tactile pavement including its good condition, the existence of zebra crossing equipped by the warning tactile, the small number of intermediaries, and the sidewalk pavement without potholes.

Table 8. Physical Factor Construct the Walkability Components

\begin{tabular}{|l|l|}
\hline \multicolumn{1}{|c|}{$\begin{array}{c}\text { Walkability } \\
\text { Component }\end{array}$} & \multicolumn{1}{|c|}{$\begin{array}{c}\text { Important Physical Factors } \\
\text { For Blind Walker }\end{array}$} \\
\hline $\begin{array}{l}\text { The width of side } \\
\text { walk }\end{array}$ & $\begin{array}{l}\text { Effective width of side walk } \\
(\mathrm{m})\end{array}$ \\
\hline $\begin{array}{l}\text { The Sidewalk } \\
\text { Pavement Condition }\end{array}$ & $\begin{array}{l}\text { Tactile pavement condition } \\
\text { Number of sidewalk } \\
\text { potholes/100 m (unit) }\end{array}$ \\
\hline $\begin{array}{l}\text { Sense of Safety in } \\
\text { Crossing }\end{array}$ & $\begin{array}{l}\text { Number of zebra crossing/ 300 } \\
\text { m (unit) }\end{array}$ \\
\hline $\begin{array}{l}\text { Physical Guidance for } \\
\text { Blind }\end{array}$ & $\begin{array}{l}\text { Existence of pavement tactile } \\
\text { Tactile pavement condition }\end{array}$ \\
\hline
\end{tabular}




\begin{tabular}{|l|l|}
\hline $\begin{array}{r}\text { Walkability } \\
\text { Component }\end{array}$ & \multicolumn{1}{|c|}{$\begin{array}{c}\text { Important Physical Factors } \\
\text { For Blind Walker }\end{array}$} \\
\hline Sense of Security & $\begin{array}{l}\text { Number of nearby house } / 100 \mathrm{~m} \\
\text { (unit) } \\
\text { Number of nearby } \\
\text { commercials/100 m (unit) }\end{array}$ \\
\hline Sidewalk Level & $\begin{array}{l}\text { Avg. number } \\
\text { intermediaries/100 m of } \\
\text { Changes in Elevation } / 100 \mathrm{~m} \\
\text { Existence of chair }\end{array}$ \\
\hline
\end{tabular}

\section{Conclusion}

This paper discover the physical attribute that construct the walkability perception of blind pedestrian. As different with the previous research that mostly focuses on the non-blind walker perception, the paper thus takes into account the blind walker perception for investigating the physical attribute of walkability perception. The result shows that the blind walker has a specific physical attributes, which needs to be carefully handled in the pedestrian facilities planning. Therefore, the result is potentially to be used for analyzing the required pedestrian facilities to serve the blind walker.

This work is supported by the P3MI ITB research project fund. We thank our colleagues from PSBN Wyta Guna Bandung who provided insight and information that greatly assisted the research.

\section{References}

1. T. Wagener, and S. Spek, Accessibility for all Eliminating barriers across Europe, NovaTerra, Connected Cities, Netherland, (2006).

2. D. Pecchini, F.Giuliani, Street crossing behavior of people with disabilities, J. Transp. Eng. 141, (2015).

3. M.S. Wright, G.K. Cook, G.M.B. Webber, Emergency lighting and wayfinding provision systems for visually impaired people: phase I of a study, Lighting Res. Technol. 3 (2), pp. 35-42, (1999).

4. E.D. Kuligowski, R. Peacock, E. Wiess, B. Hoskins, Stair evacuation of older adults and people with mobility impairments, Fire Saf. J. 62, 230-237, (2013).

5. W. Daamen, S.P. Hoogendoorn, Emergency door capacity: influence of door width, population composition and stress level, Fire Technol. 48 (1), 55-71, (2011).

6. M.C. Rodriguez-Sanchez, M.A. Moreno-Alvarez, E. Martin, S. Borromeo, J.A. Hernandez-Tamames, Accessible smartphones for blind users: A case study for a wayfinding system, Expert Systems with Applications 41, pp. 7210-7222, (2014).

7. S. Secchi, A. Lauria, G. Cellai, Acoustic wayfinding: A method to measure the acoustic contrast of different paving materials for blind people, Applied Ergonomics 58, pp. 435-445, (2017).

8. S. Mascetti, D. Ahmetovic, A. Gerino, C. Bernareggi, ZebraRecognizer: Pedestrian crossing recognition for people with visual impairment or blindness, Pattern Recognition 60, pp. 405-419, (2016).

9. S. Mascetti, D. Ahmetovic, A. Gerino, C. Bernareggi, M. Busso, A. Rizzi, Robust traffic lights detection on mobile devices for pedestrians with visual impairment, Computer Vision and Image Understanding 148, pp. 123-135, (2016).

10. S. Mascetti, D. Ahmetovic, A. Gerino, C. Bernareggi, Sonification of guidance data during road crossing for people with visual impairments or blindness, Int. J. Human-Computer Studies 85, pp. 16-26, (2016).

11. S. Handy, Critical assessment of the literature on the relationships among transportation, land use, and physical activity, Transportation Research Board and the Institute of Medicine Committee on Physical Activity, Health, Transportation, and Land Use. Resource Paper for TRB Special Report, 282, (2005).

12. S. Kalakou, and F. Moura, Bridging the gap in planning indoor pedestrian facilities, Transport Reviews, 34(4), 474-500, (2014).

13. R. Cervero, and K. Kockelman, Travel demand and the 3Ds: density, diversity and design. Transportation Research Part D: Transport and Environment, 2(3), 199-219, (1997).

14. R. Cervero, O. L. Sarmiento, E. Jacoby, L.F. Gomez, and A. Neiman, Influences of built environments on walking and cycling: lessons from bogotá, International Journal of Sustainable Transportation, 3(4), 203-226, (2009).

15. R., Ewing, \& S. Handy, Measuring the unmeasurable: urban design qualities related to walkability. Journal of Urban Design, 14(1), 65-84, (2009).

16. S. Park, E. Deakin, and J.S. Lee, Perception-based walkability index to test impact of microlevel walkability on sustainable mode choice decisions, Transportation Research Record: Journal of the Transportation Research Board, 2464(1), 126-134, (2014). 